\section{Pure Motor Stroke}

Elliot J. Roth

Department of Physical Medicine and

Rehabilitation, Northwestern University, Feinberg School of Medicine, Chicago, IL, USA

\section{Definition}

In a pure motor stroke, the only symptoms are motor dysfunction. Although hemiplegia (or hemiparesis) is most common, this can present with monoplegia or monoparesis, quadriplegia or quadriparesis, or another pattern of limb paralysis or weakness. There is a striking lack of other typical symptoms of stroke such as aphasia, cognitive deficits, sensory loss, or others. It is one of the lacunar stroke syndromes, most commonly caused by infarction of the posterior limb of the internal capsule, located in the deep white matter of the brain, but it also may be caused by an infarction in the pons.

\section{Cross-References}

Lacunar Stroke

\section{References and Reading}

Gerraty, R. P., Parsons, M. W., Barber, P. A., Darby, D. G., Desmond, P. M., Tress, B. M., et al. (2002). Examining the lacunar hypothesis with diffusion and perfusion magnetic resonance imaging. Stroke, 33, 2019-2024.

Lodder, J., \& Gorsselink, E. L. (2009). Progressive stroke caused by CT-verified small deep infarcts: Relation with the size of the infarct and clinical outcome. Acta Neurologica Scandinavica, 71, 328-330.

Norrving, B., \& Staaf, G. (1991). Pure motor stroke from presumed lacunar infarct: Incidence, risk factors and initial course. Cerebrovascular Diseases, 1, 203-209. 